\title{
Research Article Effect of Polyherbal Mixtures on the Treatment of Diabetes
}

\author{
Aparajeya Panda, ${ }^{1}$ Somanatha Jena, ${ }^{2}$ Pramod Kumar Sahu, ${ }^{3}$ \\ Sanghamitra Nayak, ${ }^{4}$ and Payodhar Padhi ${ }^{1}$ \\ ${ }^{1}$ Hi-Tech Research and Development Centre, Konark Institute of Science and Technology, Bhubaneswar, Odisha 752050, India \\ ${ }^{2}$ P.G. Department of Botany, Utkal University, Bhubaneswar, Odisha 751004, India \\ ${ }^{3}$ Department of Biotechnology, Rama Devi Women's (Auto) College, Bhubaneswar, Odisha 751022, India \\ ${ }^{4}$ Centre for Biotechnology, SOA University, Bhubaneswar, Odisha 751003, India
}

Correspondence should be addressed to Payodhar Padhi; payodharpadhi@gmail.com

Received 27 February 2013; Accepted 20 March 2013

Academic Editors: O. Giampietro and A. O. Wong

Copyright (C) 2013 Aparajeya Panda et al. This is an open access article distributed under the Creative Commons Attribution License, which permits unrestricted use, distribution, and reproduction in any medium, provided the original work is properly cited.

\begin{abstract}
The study focuses on polyherbal antidiabetic formulations of different plants used in the treatment of diabetes mixed in different concentrations. In the present study eleven medicinal plants with proven antidiabetic and related beneficial effects were selected for the preparation of five mixtures. The efficacy of prepared mixtures has been tested on streptozotocin- (STZ-) induced diabetic rats and compared with a commercially available drug glibenclamide. The mixtures at the dose levels of $400 \mathrm{mg} / \mathrm{kg}$ b.w. produced a significant decrease in blood glucose level by $69.6 \%, 70.97 \%, 64.45 \%, 71.82 \%$, and $64.44 \%$ after 21 days of treatment. The elevated level of SGPT, SGOT, and ALP in the diabetic controlled group reflected the significant alteration of liver function by STZ induction and was found to be equipotent to glibenclamide in restoration of the elevated enzyme levels to normal. The elevated lipid levels (triglyceride and total cholesterol) were restored to near normal by these mixtures for all the estimated parameters. The results of the mixtures on treated group were found to restore the glycemic level to the near normal level thereby indicating antihyperglycemic activity of the formulated mixtures.
\end{abstract}

\section{Introduction}

At present there is an extensive growth in the field of herbal mixtures, and these mixtures are gaining popularity both in developing and developed countries because of their natural origin and less side effects. Many traditional medicines are derived from medicinal plants and minerals which are used for the treatment of different chronic diseases like diabetes, asthma, and so forth [1]. Major hindrance in amalgamation of herbal medicine in modern medical practices is lack of scientific and clinical data proving their efficacy and safety. There is a need for conducting clinical research in herbal mixtures, developing simple bioassays for biological standardization, pharmacological and toxicological evaluation, and developing various animal models for toxicity and safety evaluation. It is also important to establish the active components of these herbal extracts [2].

Diabetes is a metabolic disorder characterized by increased fasting and postprandial blood sugar levels.
The prevalence of diabetes is likely to be increased by $35 \%$ [2]. It may be projected from 15 million in 1995 to 57 million in 2025 [3]. In the present study eleven plants (cited below) have been selected for preparation of five mixtures. The Ferula assa-foetida is found to reduce the body weight of alloxan-induced albino rats [4]. The Annona squamosa extract brings blood glucose levels, serum insulin levels, serum lipid profiles, and body weight to normal level in streptozotocin-nicotinamide-induced diabetic rats [5]. Fresh juice of Zingiber officinale produced a time dependent decrease in blood glucose level significantly compared to both glibenclamide and metformin in STZ-induced diabetic rats [6]. The leave extracts of Gymnema sylvestre show significant reduction in blood glucose, glycosylated haemoglobin, and glycosylated plasma proteins in diabetic patients [7]. Aqueous extract of seeds of Tamarindus indica Linn. was found to have potent antidiabetogenic activity that reduces blood sugar level in streptozotocin- (STZ-) induced diabetic male rat [8]. The aqueous extract of Azadirachta indica 
TABLE 1: Composition of mixtures.

\begin{tabular}{|c|c|c|c|c|c|c|}
\hline \multirow{2}{*}{ Sl. no. } & \multirow{2}{*}{ Herbals } & \multicolumn{5}{|c|}{ Quantity of herbals in different mixtures (in gm) } \\
\hline & & Mixture 1 & Mixture 2 & Mixture 3 & Mixture 4 & Mixture 5 \\
\hline 1 & Ferula assa-foetida & 10 & 5 & 10 & 5 & 5 \\
\hline 2 & Annona squamosa & 80 & 55 & 30 & 45 & 35 \\
\hline 3 & Zingiber officinale & 45 & 80 & 30 & 55 & 50 \\
\hline 4 & Gymnema sylvestre & 40 & 45 & 30 & 35 & 50 \\
\hline 5 & Tamarindus indica & 30 & 45 & 80 & 40 & 55 \\
\hline 6 & Azadirachta indica & 35 & 50 & 65 & 80 & 30 \\
\hline 7 & Trigonella foenum-graecum & 70 & 40 & 80 & 55 & 30 \\
\hline 8 & Moringa oleifera & 45 & 70 & 55 & 40 & 80 \\
\hline 9 & Aegle marmelos & 50 & 35 & 40 & 45 & 55 \\
\hline 10 & Cajanus cajan & 40 & 30 & 50 & 60 & 35 \\
\hline 11 & Cinnamomum tamala & 55 & 45 & 30 & 40 & 75 \\
\hline
\end{tabular}

lowers the blood glucose and improves the body weight gain in streptozotocin-induced diabetic rats [9]. The alcoholic seed extract of Trigonella foenum-graecum lowers the blood glucose level in alloxan-induced diabetic rats [10]. The ethanolic and aqueous extracts of roots of Moringa oleifera lower the blood glucose level in streptozotocin- (STZ-) induced diabetic rats [11]. The aqueous extract of Aegle marmelos seeds shows antidiabetic and hypolipidemic effects in streptozotocin-induced diabetic rats [12]. The methanolic leave extracts of Cajanus cajan reduce fasting blood sugar level in alloxan-induced diabetic rats [13]. Administration of the aqueous extracts of Cinnamomum tamala (CTLEt) leaves decreases the levels of fasting blood glucose and urine sugar, with a concomitant increase in body weight in streptozotocin-induced diabetic rats [14].

Keeping on view of the above effectiveness of the herbals for diabetics, it is proposed to formulate polyherbal mixtures that is combination of the above herbal parts which were studied and the efficacy of mixtures compared with marketed drug glibenclamide.

\section{Material and Methods}

2.1. Herbal Materials. Eleven herbal parts having antidiabetic activity were selected from the literature [4-14]. Five different mixtures were formulated by using different ratios of eleven different types of plant parts at random. The compositions of the mixtures are given in Table 1.

2.2. Preparation of Polyherbal Extracts. The fresh leaves/seeds were plucked and separated from the twigs. These were washed clearly, shade-dried, and then ground by a mechanical grinder. The coarse powder was extracted with distilled water using soxhlet at boiling temperature $\left(60^{\circ} \mathrm{C}-80^{\circ} \mathrm{C}\right)$ up to $10 \mathrm{~h}$. A dark brown coloured extract was obtained. This dark brown extract was cooled and filtered to remove the residue. The extract was concentrated on rotary evaporator under reduced pressure and then dried to get a powder. The dried powder was diluted with saline in required proportion for the study.

2.3. Acute Toxicity Studies. The lethal dose $\left(\mathrm{LD}_{50}\right)$ of the plant extract was assessed by using albino mice of either sex weighing $20-25 \mathrm{~g}$ to determine the dose. The animals were fasted overnight prior to the experimental procedures. Different doses of extract were administered by the intraperitoneal route. The $\mathrm{LD}_{50}$ was calculated according to Miller and Tainter [15]. 1/10th of lethal dose was taken as a screening dose [16].

2.4. Experimental Animals. The Wistar albino rats (200$220 \mathrm{~g}$ ) and Swiss albino mice of both sexes (20-25 g) were purchased from the animal house of Orissa University of Agriculture and Technology, Bhubaneswar, India. They had free access to standard rat pellets and water ad libitum and were maintained under standard condition at a temperature of $25 \pm 2^{\circ} \mathrm{C}$, with a $12 / 12$ light/dark cycle and $35-60 \%$ humidity.

2.5. Induction of Type II Diabetes. Diabetes was induced in experimental rats by single intraperitoneal injection of streptozotocin (80-120 mg/kg body weight/day) dissolved in $0.1 \mathrm{M}$ citrate buffer ( $\mathrm{pH} 4.5)$. Diabetes was confirmed in animals having blood glucose level more than $230 \mathrm{mg} / \mathrm{kg}$ body weight after 48 hours of STZ administration, and blood samples were analyzed by the Accu-Chek active blood glucose meter for estimation of blood glucose levels. Animals having fasting blood glucose levels higher than $230 \mathrm{mg} / \mathrm{dL}$ were considered for experiments.

2.6. Experimental Design. Animals were divided into eight groups of six rats each. The $\mathrm{LD}_{50}$ value of mixtures was $600 \mathrm{mg}$ per $\mathrm{kg}$ body weight of mice. The mixtures were administered orally $400 \mathrm{mg}$ per $\mathrm{kg}$ body weight once a day for 21 days (Table 2).

2.7. Statistical Analysis. The results are expressed as mean \pm SD. Statistical evaluation of the data was done by one-way 
TABLE 2: Administration of mixtures in diabetic rat.

\begin{tabular}{lll}
\hline Sl. no. & Groups & Type of mixture administered in rat \\
\hline 1 & Group I & $\begin{array}{l}\text { 2 mL sterilized distilled water per kg body } \\
\text { weight }\end{array}$ \\
2 & Group II & $\begin{array}{l}2 \mathrm{~mL} \text { sterilized distilled water per kg body } \\
\text { weight }\end{array}$ \\
3 & Group III & Glibenclamide (10 mg per kg body weight) \\
4 & Group IV & Mixture 1 \\
5 & Group V & Mixture 2 \\
6 & Group VI & Mixture 3 \\
7 & Group VII & Mixture 4 \\
8 & Group VIII & Mixture 5 \\
\hline
\end{tabular}

ANOVA followed by Dunnett's $t$-test. $P$ values less than 0.05 were considered to be significant.

2.8. Estimation of Biochemical Parameters. The blood samples were collected on the 22nd day from the retroorbital plexus of the rats, serum was separated, and the biochemical estimations of serum glutamic pyruvic transaminase (SGPT), serum glutamic oxaloacetic transaminase (SGOT) [17], alkaline phosphatase (ALP) [18], total protein [19], total cholesterol, and triglyceride [20].

\section{Results and Discussions}

The blood glucose level observations have been recorded in Table 3 , and the effect of the mixtures on the body weight of rat has been shown in Table 4. The effect of multiherbal extracts on some biochemical parameters like SGPT, SGOT, ALP, total protein, triglyceride, and total cholesterol in control and STZ-induced diabetes rats has been reported in Table 5. A comparison graph between individual herbals and multiherbal extracts has been shown in Figure 1.

Here we evaluated the hypoglycemic activity of the aqueous extracts of prepared in-house mixtures and the marketed drug in streptozotocin-induced diabetic rat. From Figure 1 it can be observed that the multiherbal extracts have maintained the blood glucose level below 100, which is a better result in comparison to individual herbals. As shown in Table 3 , the formulated mixtures significantly reduced the blood glucose level in STZ-induced diabetic rat. The hypoglycemic activity of mixture 1, 2, 3, 4, and 5 and glibenclamide showed $69.6 \%, 70.97 \%, 64.45 \%, 71.82 \%, 64.44 \%$, and $64.91 \%$ antidiabetic activity, respectively. All the mixtures have shown potential in their role to reduce the blood glucose level. Mixture 4 showed higher activity as compared to the other mixtures (Table 3). This may be because of the fact that some of the herbal counterparts in mixture 4 (Table 1) were not present in the others which may possess a higher antidiabetic activity. The formulated mixtures also prevent the loss of body weight in comparison to the standard drug glibenclamide (Table 4).

Diabetes is associated with alternation of plasma lipid and lipoprotein and is consequently linked to increased

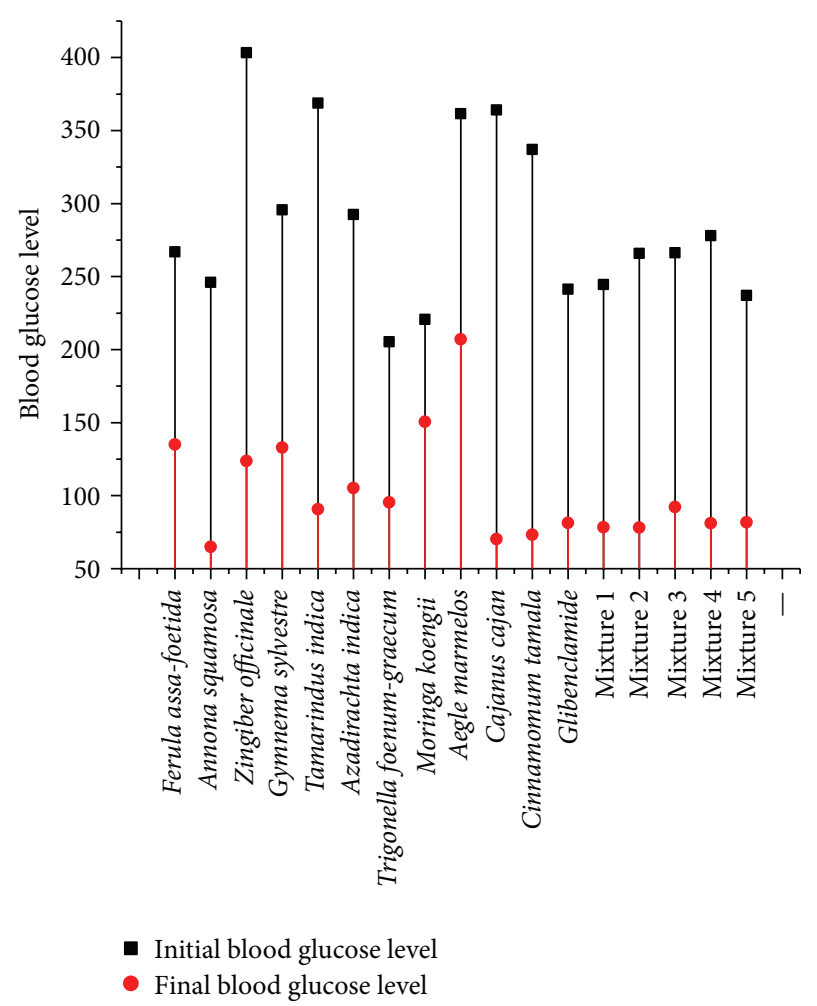

FIgURE 1: Name of the herbals and polyherbal mixtures.

risk of coronary heart disease [21]. Insulin deficiency and increased blood glucose level lead to hyperglycemia and hypercholesterolemia, as was found in the diabetic control group in the present study. This is may be due to uninhibited actions of lipolytic hormones on the fat depots and increased mobilization of free fatty acids from the fat depot. This excess fatty acid is converted into phospholipids and cholesterol in liver. The elevated lipid levels were restored to near normal in the multiherbal extracts treated groups.

The elevated levels of SGPT, SGOT, ALP, total protein, total cholesterol, and triglyceride in the diabetic control group reflected the significant alteration of liver function by STZ induction (Table 5). The extract was found to be equipotent to glibenclamide in restoration of the elevated enzyme levels to normal, implying the normal functioning of liver. Several authors have reported that flavonoids, tannins, alkaloids, and terpenes are known to be bioactive antidiabetic principles [22-24]. The antihyperglycemic effect of these mixtures may be due in part to their flavonoids, alkaloids, tannins, and terpenes.

\section{Conclusions}

The formulated mixtures on treated group were found to restore the glycemic level to the near normal level thereby indicating antihyperglycemic activity of the formulated mixtures. These formulations also restore the SGPT, SGOT, and ALP levels which indicate that they reduce the other complicacies of diabetes. A deeper insight into these herbs may lead to development of more potent antidiabetic formulations. 
TABLE 3: Antihyperglycemic activity of mixtures on STZ-induced diabetic rat.

\begin{tabular}{|c|c|c|c|c|c|c|c|c|}
\hline \multirow{2}{*}{ Group $(n=6)$} & \multirow{2}{*}{ Dose $(\mathrm{mg} / \mathrm{kg})$} & \multicolumn{7}{|c|}{ Blood glucose level (mg/dL) } \\
\hline & & $0 \mathrm{~h}$ & $2 \mathrm{~h}$ & $4 \mathrm{~h}$ & $8 \mathrm{~h}$ & $12 \mathrm{~h}$ & 21 days & $F$ value \\
\hline Normal control & $2 \mathrm{~mL} / \mathrm{kg}$ & $92.46 \pm 3.59$ & $90.66 \pm 2.57$ & $92.75 \pm 4.53$ & $89.66 \pm 2.72$ & $91.67 \pm 4.66$ & $90.68 \pm 3.22$ & 8.05 \\
\hline Diabetic control & $2 \mathrm{~mL} / \mathrm{kg}$ & $234.46 \pm 3.59$ & $240.66 \pm 2.57$ & $237.54 \pm 2.53$ & $241.54 \pm 2.66$ & $259.21 \pm 3.44$ & $255.3 \pm 2.11$ & 0.55 \\
\hline Glibenclamide & 10 & $241.33 \pm 4.26^{* *}$ & $201.83 \pm 3.65^{* *}$ & $162.56 \pm 2.33^{* *}$ & $125.33 \pm 2.32^{* *}$ & $84.66 \pm 3.11^{* *}$ & $81.33 \pm 2.12^{* *}$ & 130.58 \\
\hline Mixture 1 & 400 & $244.60 \pm 2.6^{* *}$ & $188.8 \pm 3.33^{* *}$ & $168.33 \pm 2.33^{* *}$ & $111.83 \pm 2.33^{* *}$ & $74.33 \pm 3.33^{* *}$ & $78.43 \pm 2.11^{* *}$ & 127.32 \\
\hline Mixture 2 & 400 & $265.83 \pm 2.33^{* *}$ & $196.8 \pm 3.33^{* *}$ & $155.33 \pm 2.33^{* *}$ & $107.33 \pm 2.33^{* *}$ & $77.16 \pm 2.67^{* *}$ & $78.11 \pm 2.11^{* *}$ & 121.55 \\
\hline Mixture 3 & 400 & $266.32 \pm 2.33^{*}$ & $222.6 \pm 2.67^{*}$ & $169.33 \pm 2.33^{*}$ & $127.16 \pm 2.67^{*}$ & $94.66 \pm 2.67^{*}$ & $92.12 \pm 3.12^{*}$ & 119.32 \\
\hline Mixture 4 & 400 & $278.00 \pm 2.55^{* *}$ & $151.00 \pm 2.33^{* *}$ & $135.83 \pm 2.33^{* *}$ & $128.83 \pm 2.33^{* *}$ & $78.33 \pm 3.33^{* *}$ & $81.21 \pm 4.11^{* *}$ & 100.43 \\
\hline Mixture 5 & 400 & $237.16 \pm 2.67^{*}$ & $162.6 \pm 3.67^{*}$ & $138.66 \pm 2.67^{*}$ & $108.66 \pm 2.67^{*}$ & $84.33 \pm 3.33^{*}$ & $81.76 \pm 1.21^{*}$ & 118.43 \\
\hline
\end{tabular}

Results expressed as mean $\pm \mathrm{SD}(n=6)$. Treatment was done for 21 days. The data were statistically analysed by one-way ANOVA, followed by Dunnett's $t$-test. ${ }^{*} P<0.01,{ }^{* *} P<0.05$. $P$ values less than 0.01 were considered more significant.

TABLE 4: Effect of mixtures on body weight of STZ-induced diabetic rat.

\begin{tabular}{lcccc}
\hline Groups & Initial weight $(\mathrm{gm})$ & Final weight $(\mathrm{gm})$ & Change in body weight & Change in body weight $(\%)$ \\
\hline Normal control & $210.00 \pm 8.91$ & $255.17 \pm 678$ & $45.17 \pm 6.78$ & $+28.23 \pm 3.85$ \\
Diabetic control & $231.17 \pm 8.78$ & $212.00 \pm 8.42$ & $-19.17 \pm 5.21$ & $-11.15 \pm 2.68$ \\
Diabetic + glibenclamide & $218.00 \pm 7.89^{* *}$ & $256.50 \pm 8.16^{* *}$ & $38.50 \pm 5.98^{* *}$ & $+22.65 \pm 1.08^{* *}$ \\
Diabetic + mixture 1 & $200.84 \pm 7.75^{*}$ & $222.49 \pm 6.78^{*}$ & $21.65 \pm 8.9^{*}$ & $+12.45 \pm 2.96^{*}$ \\
Diabetic + mixture 2 & $220.13 \pm 8.75^{*}$ & $243.91 \pm 5.67^{*}$ & $23.78 \pm 5.81^{*}$ & $+12.50 \pm 3.86^{*}$ \\
Diabetic + mixture 3 & $200.17 \pm 7.45^{* *}$ & $226.35 \pm 6.02^{* *}$ & $26.18 \pm 6.21^{* *}$ & $+14.37 \pm 1.96^{* *}$ \\
Diabetic + mixture 4 & $205.83 \pm 7.33^{*}$ & $221.48 \pm 7.66^{*}$ & $15.65 \pm 8.88^{*}$ & $+9.10 \pm 1.23^{*}$ \\
Diabetic + mixture 5 & $208.87 \pm 7.75^{*}$ & $229.52 \pm 7.88^{*}$ & $20.65 \pm 5.83^{*}$ & $+11.54 \pm 1.05^{*}$ \\
\hline
\end{tabular}

Results expressed as mean \pm SD $(n=6)$. Treatment was done for 21 days. The data were statistically analysed by one-way ANOVA, followed by Dunnett's $t$-test. ${ }^{*} P<0.01,{ }^{* *} P<0.05$. $P$ values less than 0.01 were considered more significant.

TABLE 5: Effect of multiherbal extracts on biochemical parameters in control and STZ-induced diabetic rats.

\begin{tabular}{|c|c|c|c|c|c|c|}
\hline Groups & SGPT (IU/dL) & SGOT (IU/dL) & $\operatorname{ALP}(\mathrm{IU} / \mathrm{dL})$ & $\begin{array}{l}\text { Total protein } \\
(\mathrm{mg} / \mathrm{dL})\end{array}$ & $\begin{array}{c}\text { Triglyceride } \\
(\mathrm{mg} / \mathrm{dL})\end{array}$ & $\begin{array}{c}\text { Total cholesterol } \\
(\mathrm{mg} / \mathrm{dL})\end{array}$ \\
\hline Normal control $(2 \mathrm{~mL} / \mathrm{kg})$ & $122.22 \pm 2.54$ & $130.51 \pm 3.77$ & & $8.30 \pm 1.87$ & $84.55 \pm 2.71$ & $138.6 \pm 3.11$ \\
\hline Diabetic control ( $2 \mathrm{~mL} / \mathrm{kg})$ & $214.33 \pm 4.40$ & $250 \pm 6.02$ & $90.5 \pm 4.53$ & $6.16 \pm 1.93$ & $214.15 \pm 5.10$ & $253.83 \pm 6.16$ \\
\hline Glibenclamide (10 mg/kg) & $110.66 \pm 3.13^{* *}$ & $140.16 \pm 4.29^{* *}$ & $46.83 \pm 4.29^{* *}$ & $8.16 \pm 1.46^{* *}$ & $109.66 \pm 3.76^{* *}$ & $124 \pm 5.92^{* *}$ \\
\hline Mixture 1 (400 mg/kg) & $130.00 \pm 4.46^{* *}$ & $160.16 \pm 3.64^{* *}$ & $51.33 \pm 5.45^{* *}$ & $5.83 \pm 2.21^{*}$ & $130.83 \pm 4.82^{* *}$ & $146.16 \pm 5.33^{* *}$ \\
\hline Mixture $2(400 \mathrm{mg} / \mathrm{kg})$ & $121.16 \pm 4.15^{* *}$ & & $49.83 \pm 5.74^{* *}$ & & $121.33 \pm 4.31^{* *}$ & $138.5 \pm 4.49^{* *}$ \\
\hline Mixture 3 (400 mg/kg) & $117.00 \pm 3.39^{* *}$ & $142.33 \pm 5.30^{* *}$ & $47.5 \pm 4.66^{* *}$ & $8 \pm 2.27^{* *}$ & $112.5 \pm 4.79^{* *}$ & $131.16 \pm 5.69^{* *}$ \\
\hline Mixture 4 (400 mg/kg) & $118.5 \pm 3.44^{* *}$ & $138.98 \pm 3.77^{* *}$ & $40.62 \pm 3.65^{* *}$ & $5.66 \pm 2.54^{*}$ & $118.34 \pm 3.56^{* *}$ & $122.44 \pm 4.23^{* *}$ \\
\hline Mixture $5(400 \mathrm{mg} / \mathrm{kg})$ & $119.33 \pm 3.56^{* *}$ & $145 \pm 3.87^{* *}$ & $48.4 \pm 5.23^{* *}$ & $6.67 \pm 4.33^{*}$ & $120.5 \pm 4.89^{* *}$ & $135.5 \pm 4.33^{* *}$ \\
\hline
\end{tabular}

Results expressed as mean $\pm \mathrm{SD}(n=6)$. Treatment was done for 21 days. The data were statistically analysed by one-way ANOVA, followed by Dunnett's $t$-test. ${ }^{*} P<0.01,{ }^{* *} P<0.05$. $P$ values less than 0.01 were considered more significant.

\section{Acknowledgments}

Special thanks to all staff of Hi-Tech Research and Development Centre, Konark Institute of Science and Technology, Bhubaneswar, for their help and technical assistance.

\section{References}

[1] I. Ahmad, F. Agil, and M. Owais, Modern Phytomedicine: Turning Medicinal Plants into Mixtures, John Wiley \& Sons, West-Sussex, UK, 2006.

[2] R. N. Okigbo, C. L. Anuagasi, and J. E. Amadi, "Advances in selected medicinal and aromatic plants indigenous to Africa,"
Journal of Medicinal Plant Research, vol. 3, no. 2, pp. 86-95, 2009.

[3] H. King, R. E. Aubert, and W. H. Herman, "Global burden of diabetes, 1995-2025: prevalence, numerical estimates, and projections," Diabetes Care, vol. 21, no. 9, pp. 1414-1431, 1998.

[4] J. K. Grover, V. Vats, S. S. Rathi, and R. Dawar, "Traditional Indian anti-diabetic plants attenuate progression of renal damage in streptozotocin induced diabetic mice," Journal of Ethnopharmacology, vol. 76, no. 3, pp. 233-238, 2001.

[5] E. G. E. Helal and M. A. Abbas, "Effect of some herbal medicine on some biochemical paramcters in diabetic rats," The Egyptian Journal of Hospital Medicine, vol. 22, pp. 98-110, 2006. 
[6] A. Shirwaikar, K. Rajendran, C. D. Kumar, and R. Bodla, "Antidiabetic activity of aqueous leaf extract of Annona squamosa in streptozotocin-nicotinamide type 2 diabetic rats," Journal of Ethnopharmacology, vol. 91, no. 1, pp. 171-175, 2004.

[7] B. Asha, K. H. Krishnamurthy, and S. Devaru, "Evaluation of anti hyperglycaemic activity of Zingiber officinale(Ginger) in albino rats," Journal of Chemical and Pharmaceutical Research, vol. 3, no. 1, pp. 452-456, 2011.

[8] K. Baskaran, B. K. Ahamath, K. R. Shanmugasundaram, and E. R. B. Shanmugasundaram, "Antidiabetic effect of a leaf extract from Gymnema sylvestre in non-insulin-dependent diabetes mellitus patients," Journal of Ethnopharmacology, vol. 30, no. 3, pp. 295-305, 1990.

[9] R. Maiti, D. Jana, U. K. Das, and D. Ghosh, "Antidiabetic effect of aqueous extract of seed of Tamarindus indica in streptozotocininduced diabetic rats," Journal of Ethnopharmacology, vol. 92, no. 1, pp. 85-91, 2004.

[10] M. Mostofa, M. E. Choudhury, M. A. Hossain, M. Z. Islam, M. S. Islam, and M. H. Sumon, "Antidiabetic effects of catharanthus roseus, azadirachta indica, allium sativum and glimepride in experimentally diabetic induced rat," Bangladesh Journal of Veterinary Medicine, vol. 5, no. 1-2, pp. 99-102, 2007.

[11] V. Vats, J. K. Grover, and S. S. Rathi, "Evaluation of antihyperglycemic and hypoglycemic effect of Trigonella foenumgraecum Linn, Ocimum sanctum Linn and Pterocarpus marsupium Linn in normal and alloxanized diabetic rats," Journal of Ethnopharmacology, vol. 79, no. 1, pp. 95-100, 2002.

[12] M. Panchal, B. Shah, K. Murti, and M. Shah, "Phytochemical investigation and antidiabetic activity studies of moringa oliefera roots," Research Journal of Pharmacology and Pharmacodynamics, vol. 3, no. 5, pp. 268-277, 2011.

[13] A. N. Kesari, R. K. Gupta, S. K. Singh, S. Diwakar, and G. Watal, "Hypoglycemic and antihyperglycemic activity of Aegle marmelos seed extract in normal and diabetic rats," Journal of Ethnopharmacology, vol. 107, no. 3, pp. 374-379, 2006.

[14] A. C. Ezike, P. A. Akah, C. C. Okoli, and C. B. Okpala, "Experimental evidence for the antidiabetic activity of cajanus cajan leaves in rats," Journal of Basic and Clinical Pharmacy, vol. 1, no. 2, pp. 81-84, 2010.

[15] U. Chakraborty and H. Das, "Antidiabetic and antioxidant activities of Cinnamomum tamala leaf extracts in Stz-treated diabetic rats," Global Journal of Biotechnology \& Biochemistry, vol. 5, no. 1, pp. 12-18, 2010.

[16] M. N. Ghosh, Fundamentals of Experimental Pharmacology, Hilton, Kolkata, India, 3rd edition, 2005.

[17] G. E. Paget and J. M. Barnes, Evaluation of Drug Activities: Pharmacometrics, Academic Press, New York, NY, USA, 1983.

[18] S. Reitman and S. Frankel, "A colorimetric method for the determination of serum glutamic oxalacetic and glutamic pyruvic transaminases," American Journal of Clinical Pathology, vol. 28, no. 1, pp. 56-63, 1957.

[19] P. R. Kind and E. J. King, "Estimation of plasma phosphatase by determination of hydrolysed phenol with amino-antipyrine," Journal of Clinical Pathology, vol. 7, no. 4, pp. 322-326, 1954.

[20] O. H. Lowry, N. J. Rosebrough, A. L. Farr, and R. J. Randall, "Protein measurement with the Folin phenol reagent," The Journal of Biological Chemistry, vol. 193, no. 1, pp. 265-275, 1951.

[21] L. B. Foster and R. T. Dunn, "Stable reagents for determination of serum triglycerides by a colorimetric Hantzsch condensation method," Clinical Chemistry, vol. 19, no. 3, pp. 338-340, 1973.
[22] I. Ahmed, M. S. Lakhani, M. Gillett, A. John, and H. Raza, "Hypotriglyceridemic and hypocholesterolemic effects of anti-diabetic Momordica charantia (karela) fruit extract in streptozotocin-induced diabetic rats," Diabetes Research \& Clinical Practice, vol. 51, no. 3, pp. 155-161, 2001.

[23] B. K. Rao, P. Renuka Sudarshan, M. D. Rajasekhar, N. Nagaraju, and C. Appa Rao, "Antidiabetic activity of Terminalia pallida fruit in alloxan induced diabetic rats," Journal of Ethnopharmacology, vol. 85, no. 1, pp. 169-172, 2003.

[24] A. Shirwaikar, K. Rajendran, C. D. Kumar, and R. Bodla, "Antidiabetic activity of aqueous leaf extract of Annona squamosa in streptozotocin-nicotinamide type 2 diabetic rats," Journal of Ethnopharmacology, vol. 91, no. 1, pp. 171-175, 2004. 


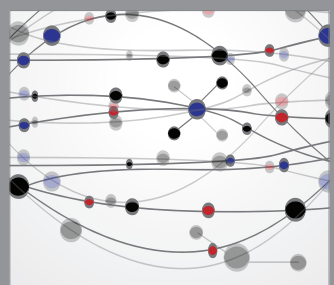

The Scientific World Journal
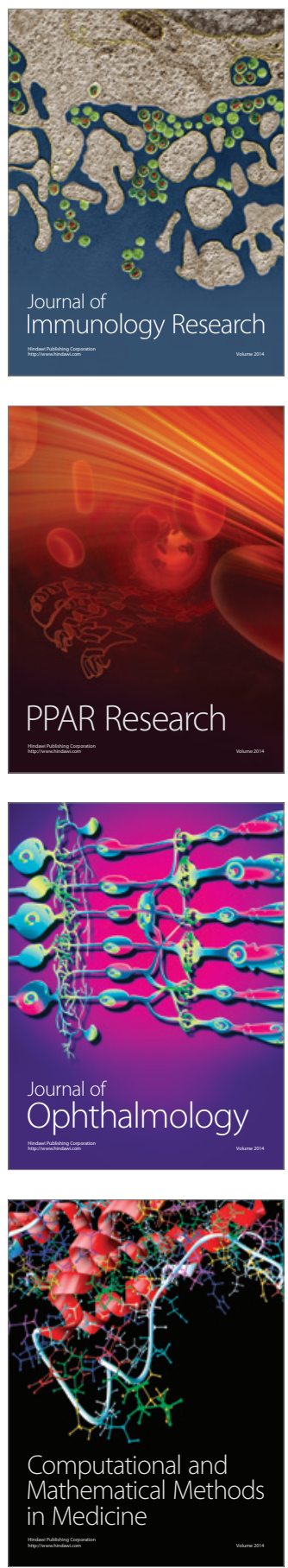

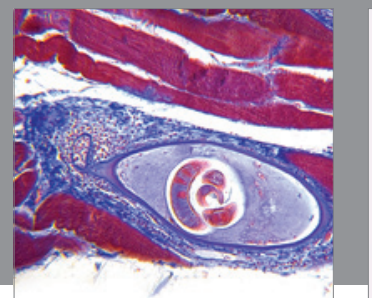

Gastroenterology

Research and Practice
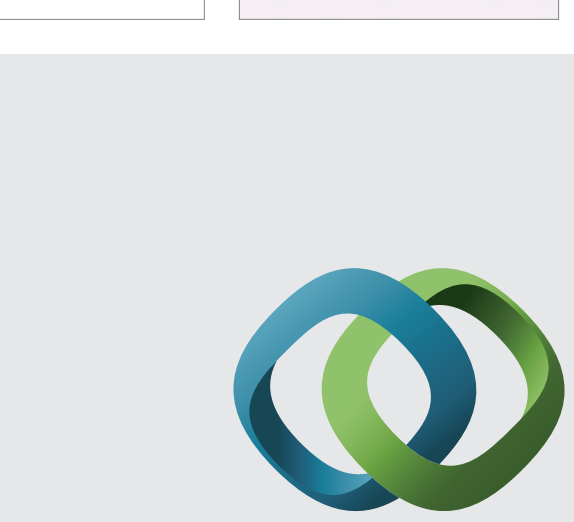

\section{Hindawi}

Submit your manuscripts at

http://www.hindawi.com
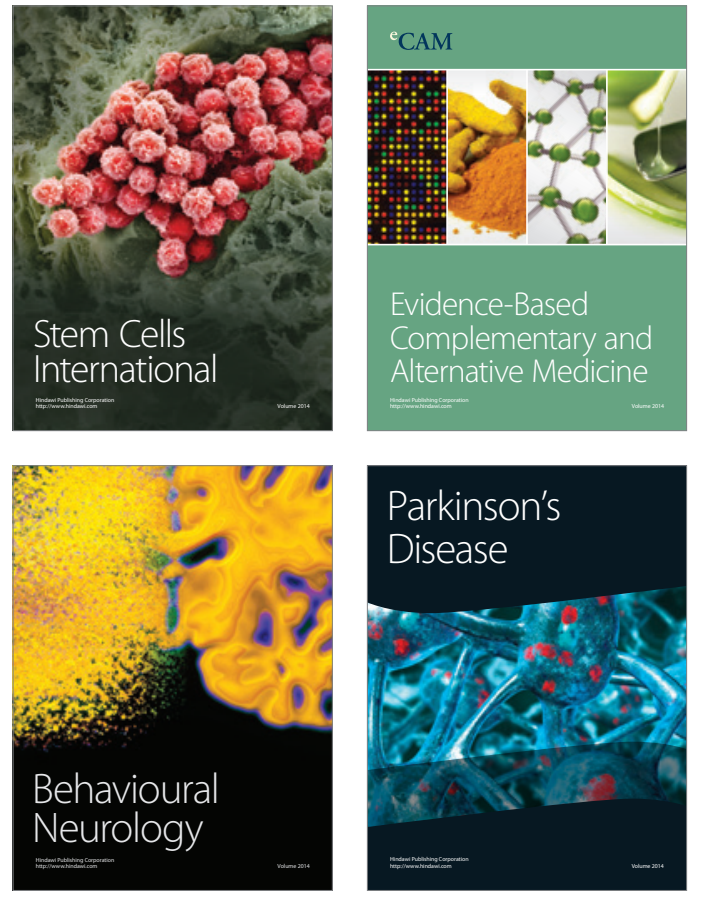
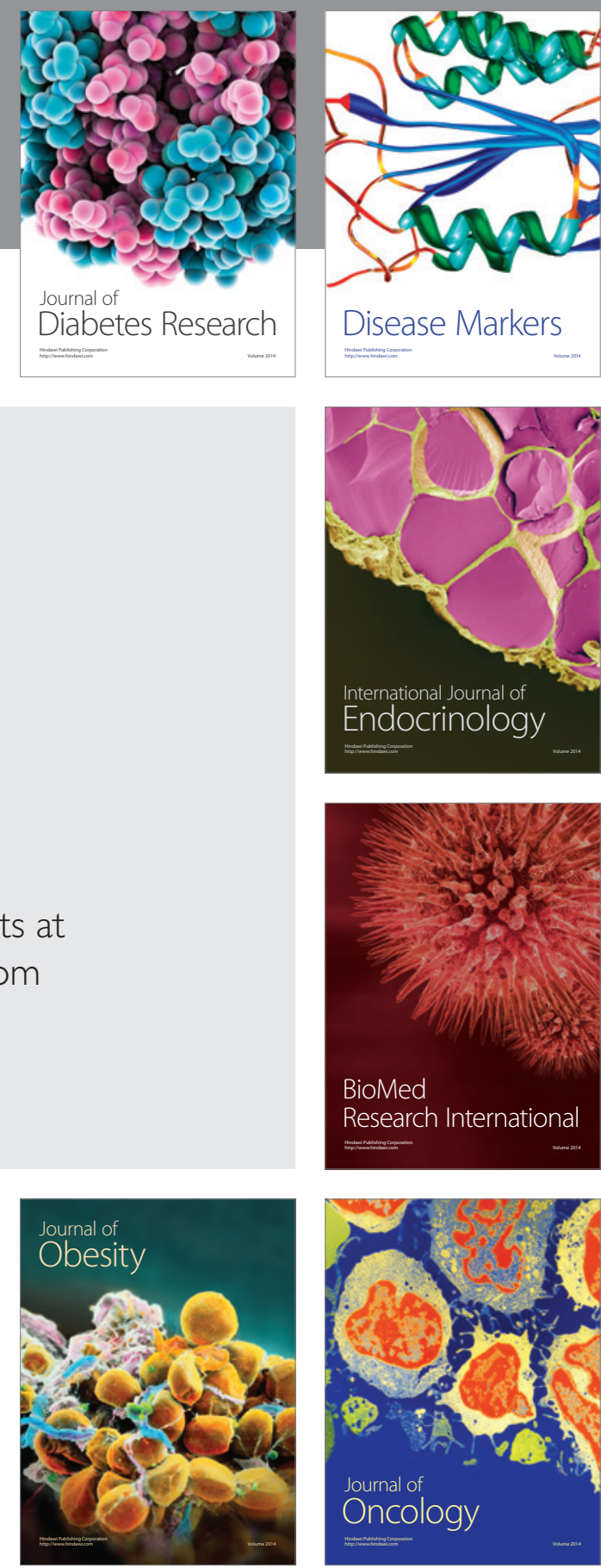

Disease Markers
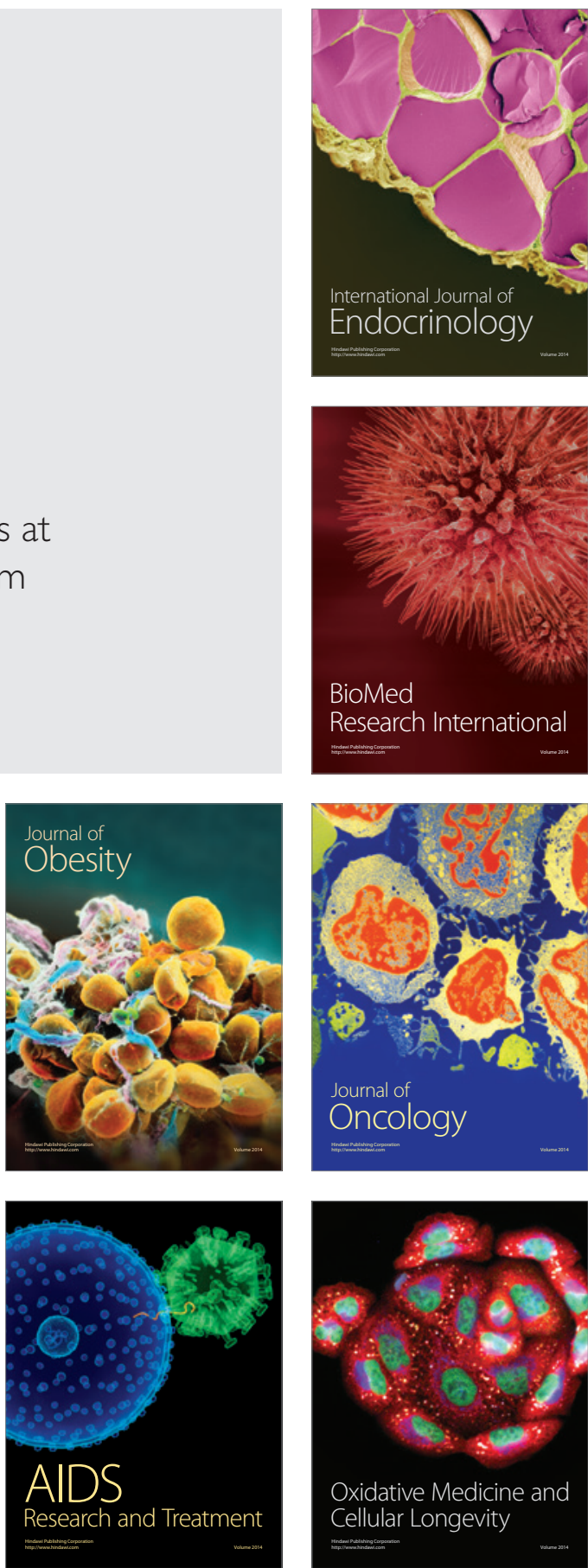